\title{
MR-Guided HIFU Treatment of Symptomatic Uterine Fibroids Using Novel Feedback-Regulated Volumetric Ablation: Effectiveness and Clinical Practice
}

\author{
MR-gesteuerte HIFU-Behandlung symptomatischer Uterusmyome mit \\ neuartiger „Feedback“-regulierter volumetrischer Ablation: Effektivität \\ und klinische Praxis
}

Authors

H. Ruhnke ${ }^{1}$, T. Eckey ${ }^{2}$, M. K. Bohlmann ${ }^{3}$, M. P. Beldoch', A. Neumann ${ }^{1}$, A. Agic ${ }^{3}$, J. Hägele ${ }^{1}$, K. Diedrich ${ }^{3}$, J. Barkhausen ${ }^{1}$, P. Hunold ${ }^{1}$

Affiliations

Clinic for Radiology and Nuclear Medicine, University Hospital Schleswig-Holstein, Campus Lübeck, Lübeck/Germany

2 Institute for Neuroradiology, University Hospital Schleswig-Holstein, Campus Lübeck, Lübeck/Germany

Department of Gynecology and Obstetrics, University Hospital Schleswig-Holstein, Campus Lübeck, Lübeck/Germany

\author{
Key words \\ - uterus \\ - ablation procedures \\ interventional MR \\ - leiomyoma \\ - technical aspects
}

eingereicht 6.8 .2012

akzeptiert 14.2.2013

Bibliography

Dol http://dx.doi.org/

10.1055/s-0033-1335289

Published online: 24.7.2013

Fortschr Röntgenstr 2013; 185 :

983-991 @ Georg Thieme

Verlag KG Stuttgart · New York .

ISSN 1438-9029

\section{Correspondence}

Priv.-Doz. Dr. Peter Hunold Clinic for Radiology and Nuclear Medicine, University Hospital Schleswig-Holstein, Campus Lübeck

Ratzeburger Allee 160

23562 Lübeck

Tel.: ++49/451/5006552

Fax: ++49/4 51/5006497

Peter.Hunold@uk-sh.de

\section{Abstract \\ $\nabla$}

Purpose: To evaluate a novel feedback-regulated volumetric sonication method in MRguided HIFU treatment of symptomatic uterine fibroids.

Materials and Methods: 27 fibroids with an average volume of $124.9 \pm 139.8 \mathrm{cc}$ in 18 women with symptomatic uterine fibroids were ablated using the new HIFU system Sonalleve (1.5 T MR system Achieva, Philips). 21 myomas in 13 women were reevaluated 6 months later. Standard (treatment) cells (TC) and feedbackregulated (feedback) cells (FC) with a diameter of $4,8,12$, and $16 \mathrm{~mm}$ were used and compared concerning sonication success, diameter of induced necrosis, and maximum achieved temperature. The non-perfused volume ratio (NPV related to myoma volume) was quantified. The fibroid volume was measured before, 1 month, and 6 months after therapy. Symptoms were quantified using a specific questionnaire (UFS-QoL).

Results: In total, 205 TC and 227 FC were applied. The NPV ratio was $23 \pm 15 \%(2-55)$. The TC were slightly smaller than intended $(-3.9 \pm 52 \%$; range, $-100-81)$, while the FC were $20.1 \pm 25.3 \%$ bigger $(p=0.02)$. Feedback mechanism is less diversifying in diameter $(p<0.001)$. Overall, the FC correlate well with the planned treatment diameter $(r=0.79)$, other than the TC $(r=0.38)$. Six months after therapy, the fibroid volume was reduced by $45 \pm 21 \%(5-100)(p=0.001)$. The symptoms decreased significantly $(\mathrm{p}=0.001)$. No serious adverse events were recorded.

Conclusion: Use of volumetric sonication leads to homogenous heating and sufficient necrosis. It is a safe and effective therapy for treating symptomatic uterine fibroids. Successful sonication of feedback cells leads to more contiguous necrosis in diameter and a less diversifying temperature.

Key Points:

- MR-guided HIFU ablation of symptomatic uterine fibroids is a valuable treatment option.

- By non-invasive HIFU fibroid volumes can be reduced and symptoms improved.

- The novel feedback-regulated treatment cells offer advantages over standard treatment cells.

Citation Format:

- Ruhnke H, Eckey T, Bohlmann M K etal. MR-Guided HIFU Treatment of Symptomatic Uterine Fibroids Using Novel Feedback-Regulated Volumetric Ablation: Effectiveness and Clinical Practice. Fortschr Röntgenstr 2013; 185: 983-991

\section{Zusammenfassung \\ $\nabla$}

Ziel: Evaluation einer neuartigen, volumetrischen Sonifikationsmethode mittels Feedback-Regulation in der MR-gesteuerten HIFU-Therapie symptomatischer Uterusmyome.

Material und Methoden: 27 symptomatische Uterusmyome mit einer Größe von 124,9 $\pm 139,8 \mathrm{ml}$ bei 18 Patientinnen wurden mit dem neuen HIFUSystem Sonalleve (1,5T MRT Achieva, Philips) behandelt, 21 Myome von 13 Pat. wurden nach 6 Monaten nachuntersucht. Bei der Therapie wurden Standard-Therapiezellen (TC) und Feedback-kontrollierte Therapiezellen (FC) mit den Durchmessern 4, 8, 12 und $16 \mathrm{~mm}$ benutzt und hinsichtlich Erfolgsrate, Durchmesser der induzierten Nekrose und Temperaturentwicklung verglichen. Die Ausdehnung der induzierten Nekrose (NPV) wurde bestimmt. Die Myomvolumina wurden vor, 1 und 6 Monate nach Therapie ausgemessen und die 
Symptomatik mittels eines spezifischen Fragebogens (UFS-QoL) bewertet.

Ergebnisse: Es wurden 205 TC durchgeführt und 227 FC. Dabei wurde ein NPV-Anteil der Myome von $23 \pm 15 \%$ (2 - 55) induziert. TC sind im Durchmesser 3,9 $\pm 52 \%(-100-81)$ kleiner als geplant, FC dagegen $20,1 \pm 25,3 \%(-100-70)$ größer $(p=0,02)$. Die Größenvarianz der Nekrosen mit Feedback-Mechanismus ist geringer ( $p<0,001)$, FC zeigen insgesamt eine gute Korrelation zum geplanten Zelldurchmesser $(r=0,79)$, anders als TC $(\mathrm{r}=0,38)$. Nach 6 Monaten war das Myomvolumen um $45 \pm 21 \%$ $(5-100)$ reduziert $(p=0,001)$. Die Symptomatik konnte signifikant reduziert werden $(p=0,001)$ Es traten in der Nachsorge keinerlei unerwünschte Nebenwirkungen auf.

Schlussfolgerung: Die Anwendung der volumetrischen Sonifikation mittels Feedback-regulierter Therapiezellen führt zu kontrollierter Erwärmung und suffizienter Nekrotisierung und stellt damit eine sichere und effektive Therapiemethode dar. Dies bestätigt die MR-gesteuerte HIFU als nicht invasives und attraktives Verfahren bei symptomatischen Uterusmyomen.

\section{Introduction}

$\nabla$

Due to their high prevalence rate, uterine fibroids are a clinically relevant problem: Up to $25 \%$ of women of reproductive age have myomas [1] and one-third of those patients are symptomatic. The established treatment options include conservative medication-based treatment, surgical treatment, and the minimally invasive uterine artery embolization (UAE) procedure [2-4]. High-intensity focused ultrasound (HIFU) makes it possible to perform completely noninvasive thermoablation of uterine fibroids on an outpatient basis. In the past HIFU has proven to be a safe and effective treatment alternative that achieves a good success rate while preserving the neighboring tissue [5-7]. MRI guidance of HIFU ablation allows precise treatment planning and real-time monitoring of the energy transfer ("sonication"), creates temperature maps of the treated tissue, and records the amount of thermal energy applied, thus making it possible to effectively control treatment and make predictions about therapeutic success $[8,9]$.

The first version of the Sonalleve ${ }^{\circledR}$ HIFU module developed by Philips HealthCare (Best, The Netherlands) in connection with the $1.5 \mathrm{~T}$ or $3 \mathrm{~T}$ MRI scanners of the Achieva and Ingenia class uses a novel method for ablating larger volumes. "Volumetric sonication" replaces the previously used pointby-point ablation technique of first-generation HIFU systems in order to make it possible to treat larger areas via ultrasound with dynamic focusing ( $\bullet$ Fig. 1). The objective is to treat large volumes more quickly in order to increase treatment efficiency. Moreover, the new system includes temperature feedback control which regulates the ablation time as a function of the measured temperature resulting in greater reliability of sonication success. Regulation is performed with the help of real-time temperature mapping and varies the duration of sonication until the necessary thermal dose for complete ablation of the tissue is achieved. The objective of this study was to evaluate the efficiency, tolerability, and therapy effect of the Sonalleve ${ }^{\circledR}$ HIFU system via feedback-regulated ablation for treating symptomatic uterine fibroids.

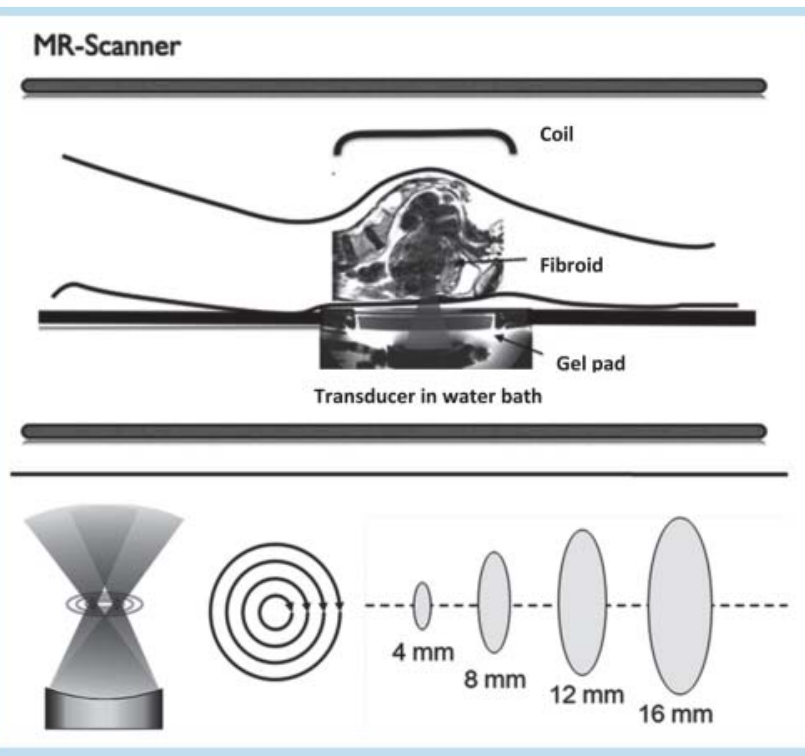

Fig. 1 Top: Schematic representation of the patient position in the MRI scanner with the HIFU transducer integrated in the examination table (Figure from [20]. With the kind permission of Springer Science+Business Media). Bottom: Principle of volumetric focusing of the ultrasound focus for inducing necroses with a diameter of up to $16 \mathrm{~mm}$ by electronically steering the focus in concentric circles in an outward direction.

\section{Materials and Methods}

$\nabla$

\section{Patients}

In the present study 27 myomas in 18 symptomatic patients were treated with HIFU (refer to $\bullet$ Table 1 for inclusion and exclusion criteria). The study was approved by the institutional review baord of the University of Lübeck. All patients were able to be followed up over a period of one month and 13 of the 18 patients (21 of the 27 myomas) were reevaluated clinically and via MRI after 6 months. The patients were $47 \pm 4$ years old (range: $40-53$ ) and the BMI was 23 $\pm 3 \mathrm{~kg} / \mathrm{m}^{2}(20-26)$. The 27 treated myomas were located intramural $(n=17)$, submucosal $(n=6)$, or subserosal $(n=4)$. All patients were experiencing myoma-associated symptoms to varying degrees ( $\triangle$ Table 2 ). The size of the myomas prior to treatment was $125 \pm 140 \mathrm{ml}(6-520)$.

\section{Preliminary diagnostics in the study}

After gynecological examination and interdisciplinary determination of the treatment indication, a preparatory MRI examination of the patient in a prone position to simulate therapy (1.5 T Achieva in diagnostic mode) was performed to clarify whether the myomas were suitable for HIFU treatment. The myomas to be treated were evaluated via diagnostic T2-weighted MRI (turbo spin echo $3 \mathrm{D}$, TR $1000 \mathrm{~ms}$, TE $130 \mathrm{~ms}$, slice thickness $5.0 \mathrm{~mm}$, slice gap $0.5 \mathrm{~mm}$, flip angle $90^{\circ}$ ) in sagittal slice orientation and via coronal and sagittal fat-saturated T1-weighted MRI before and after contrast administration (fat-saturated spoiled gradient echo, TR $6.6 \mathrm{~ms}$, TE $3.3 \mathrm{~ms}$, slice thickness $2.5 \mathrm{~mm}$, flip angle $10^{\circ}$ ). To detect any intestinal interposition, 3D-balanced fastfield-echo (bFFE) sequences (balanced steady-state free precession [bSSFP]) (TR $3.75 \mathrm{~ms}$, TE $1.9 \mathrm{~ms}$, slice thickness 
Table 1 Inclusion and exclusion criteria

\begin{tabular}{lc}
\hline inclusion criteria & exclusion criteria \\
\hline - known symptomatic uterine & - serious systemic diseases \\
fibroid(s) & - existing pregnancy or desire \\
- age between 18 and 59 years & to become pregnant \\
- weight $<140 \mathrm{~kg} / \mathrm{BMI}<35$ & - significant abdominal wall \\
- premenopausal or perimeno- & scarring \\
pausal & - general MRI contraindications \\
- symptom severity score $\geq 30$ & - calcification of the uterine \\
- pap smear l or pap smear II & fibroid \\
- dominant myoma $\geq 3 \mathrm{~cm}$ and & - intraabdominal scarring or \\
$\leq 12 \mathrm{~cm}$ & surgical clips
\end{tabular}

Table 2 Symptoms of the patients (multiple symptoms possible)

\begin{tabular}{|c|c|c|}
\hline symptom & $\begin{array}{l}\text { absolute } \\
\text { frequency }\end{array}$ & $\begin{array}{l}\text { frequency } \\
\text { in } \%\end{array}$ \\
\hline severe bleeding/hypermenorrhea & 15 & 83 \\
\hline pollakiuria & 11 & 61 \\
\hline pain/dysmenorrhea & 7 & 39 \\
\hline feeling of tension and pressure & 6 & 33 \\
\hline fluctuation of duration of period & 5 & 28 \\
\hline meteorism & 5 & 28 \\
\hline passing of blood clots & 4 & 22 \\
\hline tiredness & 4 & 22 \\
\hline nycturia & 3 & 17 \\
\hline obstipation & 2 & 11 \\
\hline
\end{tabular}

$5.0 \mathrm{~mm}$, slice gap $0.5 \mathrm{~mm}$, flip angle $20^{\circ}$ ) in sagittal slice orientation were also generated on the day of treatment.

\section{Treatment}

The HIFU transducer (Imasonic SA, Besançon, France) is integrated into the MR examination table and can be moved mechanically and tilted within the surrounding water bath in both a horizontal and vertical direction. A gel pad was positioned on the window of the transducer in the MR table to ensure that there was no air between the transducer and the target region, in particular between the gel pad and the skin (๑ Fig. 1).

After thorough abdominal depilation to ensure a smooth skin surface, a peripheral indwelling venous cannula was inserted into all patients for the administration of a nonopioid analgesic (Paracetamol, Perfalgan ${ }^{\circledR} 1000 \mathrm{mg} / 100 \mathrm{ml}$ infusion solution, Bristol-Myers Squibb) prior to treatment and for the administration of the MRI contrast agent Gadobutrol after the completion of sonication (Gadovist ${ }^{\circledR}$ $0.1 \mathrm{mmol} / \mathrm{kg} \mathrm{KG}$, Bayer HealthCare). In addition to intravenous pain prophylaxis, the patients received an oral nonsteroidal analgesic (Ibuprofen, Ibu-ratiopharm ${ }^{\circledR}, 400 \mathrm{mg}$, Ratiopharm) and a mild oral sedative upon request (Diazepam-ratiopharm ${ }^{\circledR}$ drops $10 \mathrm{mg} / \mathrm{ml}$, Ratiopharm). A urinary catheter was not used for the sake of the patients' comfort. After correct positioning of the patient over the transducer and elimination of interfering air bubbles between the abdominal skin and the gel pad via "BubbleScan" in coronal slice orientation (T1 fast field echo, TR $120 \mathrm{~ms}$, TE $15 \mathrm{~ms}$, slice thickness $2.5 \mathrm{~mm}$, flip angle $60^{\circ}$ ), T2-weighted planning images (turbo spin echo 3 D, TR $1000 \mathrm{~ms}$, TE $130 \mathrm{~ms}$, slice thickness $2.5 \mathrm{~mm}$, flip angle $90^{\circ}$ ) were acquired in sagittal slice orientation. During treatment, the planning sequences were repeated every ten minutes to adapt the sonication planning to interim uterine movements, e.g. due to filling of the bladder.

The individual "treatment cell locations" were planned with the help of multiplanar reconstructions of this sequence. Treatment cells with a diameter of $4,8,12$, or $16 \mathrm{~mm}$ with and without the feedback mechanism could be selected. A treatment cell refers to the target tissue region heated per sonication in the targeted volume ( $\bullet$ Fig. $\mathbf{1})$. The transducer generates the energy via 256 individual elements with a slightly concave design. Phased-array technology and mechanical deflection of the entire transducer are used to control and move the ultrasound focus. The selection was made based on the myoma size and generous safety distances according to the currently valid recommendations of the FDA [10]. Under consideration of the optimum treatment cell size for the individual treatment, conventional treatment cells (TC) and feedback-regulated treatment cells (feedback cells, FC) were used with approximately the same frequency without randomization for every myoma (205 vs. 227) ( $\bullet$ Fig. 2). For better assessability, only the successfully completed ablations of the TC and FC were compared.

The ultrasound energy was selected based on the temperature development of a test sonication with 20-50 watts with the average value being $130 \pm 28$ watts $(70-200)$. Visual monitoring of the sonication using real-time temperature maps via proton resonance frequency change was an important tool during treatment [11]. The visual monitoring by the operators was supported by the measurement of the introduced thermal dose and automatic stopping of the sonication by the HIFU software once the planned volume was reached. The system acquires images of a total of six different slices every three seconds. The temperature development can be tracked on screen on four different levels with color coding. Three adjacent coronal slices and one sagittal slice in the direction of the beam field as well as one previously defined slice to monitor the tissue in front of the beam focus (near field) and one behind the beam focus (far field) were imaged to visualize the heating of the treatment cell. These planes were positioned in particularly sensitive anatomical regions ( $\bullet$ Fig. 3), i. e., one at the level of the abdominal wall (risk of cavitation), and the other at the level of the front wall of the sacrum (risk of damage to the neural structures). Both the patient and operator were able to stop each sonication at any time by pressing the cancel button.

After completed treatment, the patients underwent clinical examination and were briefly monitored before being allowed to leave the hospital on the same day.

\section{Evaluation}

\section{Treatment efficiency}

To estimate the treatment efficiency, the non-perfused volume (NPV) was determined via manual segmentation and addition of the determined volumes (slice summation) in the contrast-enhanced, T1-weighted MRI images (fat-saturated spoiled gradient echo, TR $6.6 \mathrm{~ms}$, TE $3.3 \mathrm{~ms}$, slice thickness $2.5 \mathrm{~mm}$, flip angle $10^{\circ}$ ) directly following treatment. The values were used to determine the percentage of the myoma that was no longer perfused, i.e., the NPV ratio. To evaluate all treatment cells and to compare the used TC 


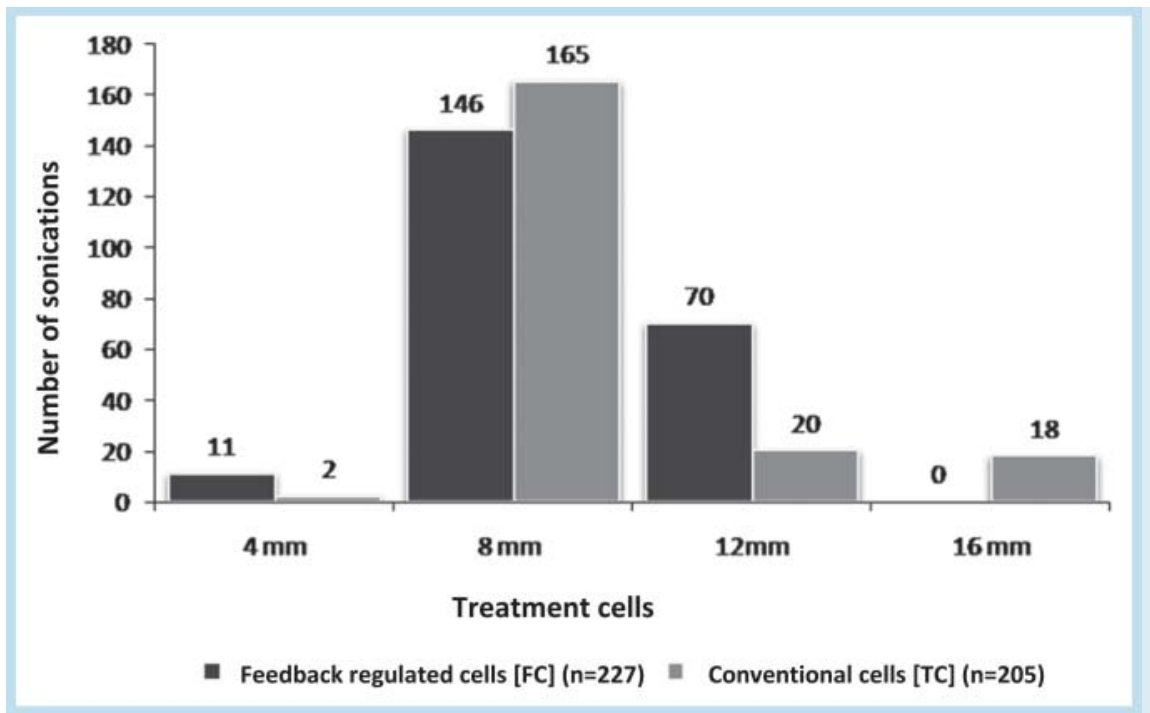

Fig. 2 Overview of the number and size of used treatment cells. Feedback-regulated treatment cells are referred to as feedback cells $(\mathrm{FC})$ and treatment cells without feedback regulation are referred to as treatment cells (TC).

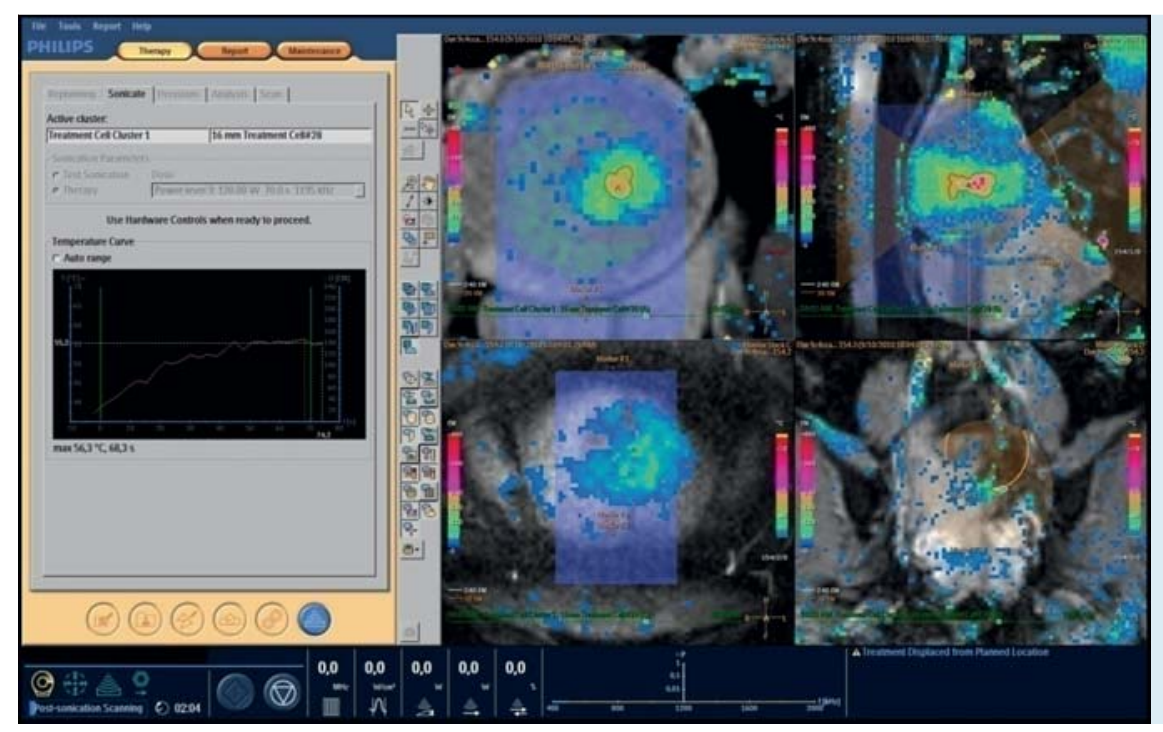

Fig. 3 Treatment monitoring via color-coded MR thermometry with visualization of the ultrasound focus in coronal and sagittal view and from the near and far field in coronal slice orientation. Simultaneous representation of the temperature development in the ultrasound focus over time (left).

and FC, the diameter of all sonications visualized per MR thermometry was determined as a measure for the volume and the deviation from the previously planned size was determined. The induced tissue necrosis was calculated and visualized according to Sapareto, i.e., a virtual exposure time at a reference temperature was calculated on the basis of the currently measured temperature as a function of time and an estimated time-temperature relationship [12]. A thermal energy of 240 equivalent minutes in relation to $43^{\circ} \mathrm{C}$ was considered a lethal dose for the tissue area and represented by the monitoring software as an isodose. The area covered by this isodose was evaluated as tissue necrosis and measured after completed treatment at the HIFU planning console. The ablation success or stopping criterion was documented for every sonication. The highest temperature per sonication was recorded and compared between the TC and FC.

\section{Tolerability}

The tolerability of the treatment was determined via patient questionnaire concerning the status before, during, and immediately after treatment. The level of pain was indicated using a 4 -point scale $(0=$ no pain; $1=$ minor pain; 2 = moderate pain; 3 =severe pain). In addition, all periinterventional incidents and treatment-based complaints during treatment and for a follow-up period of 6 months were documented. The total treatment time, i.e., the MRI examination time, the time period from the first to the last sonication, and the duration of stay in the hospital, was recorded.

\section{Volume reduction}

Treatment was followed by a follow-up MRI examination after one month and after 6 months to evaluate the clinical success. The primary treatment success in terms of volume reduction was determined using volumetry of the treated myomas via manual segmentation prior to treatment and in the follow-up examinations.

\section{Symptom reduction}

Myoma-related symptom changes were recorded using a standardized questionnaire prior to treatment and 1 month 
and 6 months after treatment. The questionnaire established and used for this purpose, UFS-QoL (Uterine Fibroid Symptoms - Quality of Life), was developed specifically for myoma-related symptoms and evaluated for the minimally invasive treatment of symptomatic uterine fibroids and diseases with similar symptoms, such as uterine adenomyosis $[13,14]$. The symptom severity score (SSS), which specifies the severity of symptoms on a scale of 0 to 100 with high values indicating severe symptoms, was calculated with the help of the questionnaire. A significant treatment effect is assumed for a point reduction of $\geq 10$ points.

\section{Statistics}

Statistical data were specified as the mean \pm standard deviation and the range in parentheses. Significance tests were performed according to normal distribution testing via Ttest for independent and paired samples and Mann-Whitney-U and Wilcoxon testing for not normally distributed variables with a significance level of $\mathrm{p}<0.05$. The variance was assessed using the Levene test. Spearman's correlation coefficient was used to determine the correlation.

\section{Results}

$\nabla$

No serious incidents occurred during or after treatment. Treatment was stopped prior to reaching the planned sonication volume in 3 of 18 cases due to pain and a further termination occurred as the result of hardware problems. All patients were able to leave the hospital on the same day and resume normal activities the next day.

A total of 432 sonications were performed in all treatments. The average treatment time (period in which the patient was in the MR scanner) was $244 \pm 45 \mathrm{~min}(150-310)$, and the time from the first to the last sonication was $140 \pm 37 \mathrm{~min}$ $(92-220)$. The entire hospital stay for treatment (period from entering to leaving the hospital) was $380 \pm 71 \mathrm{~min}$. $(240-525)$.

\section{Treatment efficiency}

The primary NPV ratio achieved during treatment was $23 \pm 15 \%$ ( $2-55)$. The largest primarily no longer perfused volume was $128 \mathrm{ml}$ in a $234 \mathrm{ml}$ myoma. Dividing the study population into 2 groups according to chronological order of treatment as an indicator for the influence of the experience of the operator on treatment success showed that the NPV ratio increased significantly from $14 \pm 10 \%(2-30)$ to $30 \pm 15 \%(3-55)(\mathrm{p}=0.007)$.

The average maximum temperature of all sonications was $63.1 \pm 8.4^{\circ} \mathrm{C}(40-92) .89 \%$ reached a maximum temperature of at least $56^{\circ} \mathrm{C}$, while only $1.6 \%$ reached an excessive temperature of more than $80^{\circ} \mathrm{C}$. $\diamond$ Fig. 4 provides an overview of the temperature development of all performed sonications.

A large number of feedback sonications could not be completed according to protocol in the manner defined by the system for the particular treatment cell. Only $28.6 \%$ (65 of 227) were completed properly according to protocol. 113/ 227 sonications (50\%) were stopped due to error messages or warnings (in particular failure to reach the target thermal dose). However, sufficient ablation could be assumed in most cases on the basis of the temperature development observed by the operator so that the reason for the error message was often unclear. The percentage of terminations increased with the size of the treatment cell. Using the conventional method (TC), $83.4 \%$ (171 of 205) of the sonications were completed as planned. A more detailed overview of the consistency and stopping criteria of the TC and FC is provided in 0 Table 3.

Compared to the temperature development, using the FC results in significantly higher maximum temperatures than in the case of the TC: $66.7 \pm 4.6^{\circ} \mathrm{C}(57-87)$ vs. $63.1 \pm 7.8^{\circ} \mathrm{C}$ $(48-127), p=0.000001$. The temperature variance is lower when using the FC $(\mathrm{p}=0.01)$.

The following applies for the correlation of the actually resulting NPV to the size of the selected treatment cell: The actual NPV of the TC is $3.9 \pm 52 \%(-100-81)$ smaller than planned (according to Sapareto) while that of the FC is $20.1 \pm 25.3 \%(-100-70)$ greater than expected $(p=0.02)$. The variance of the feedback mechanism is also lower here, and the average deviations from the planned treatment cell






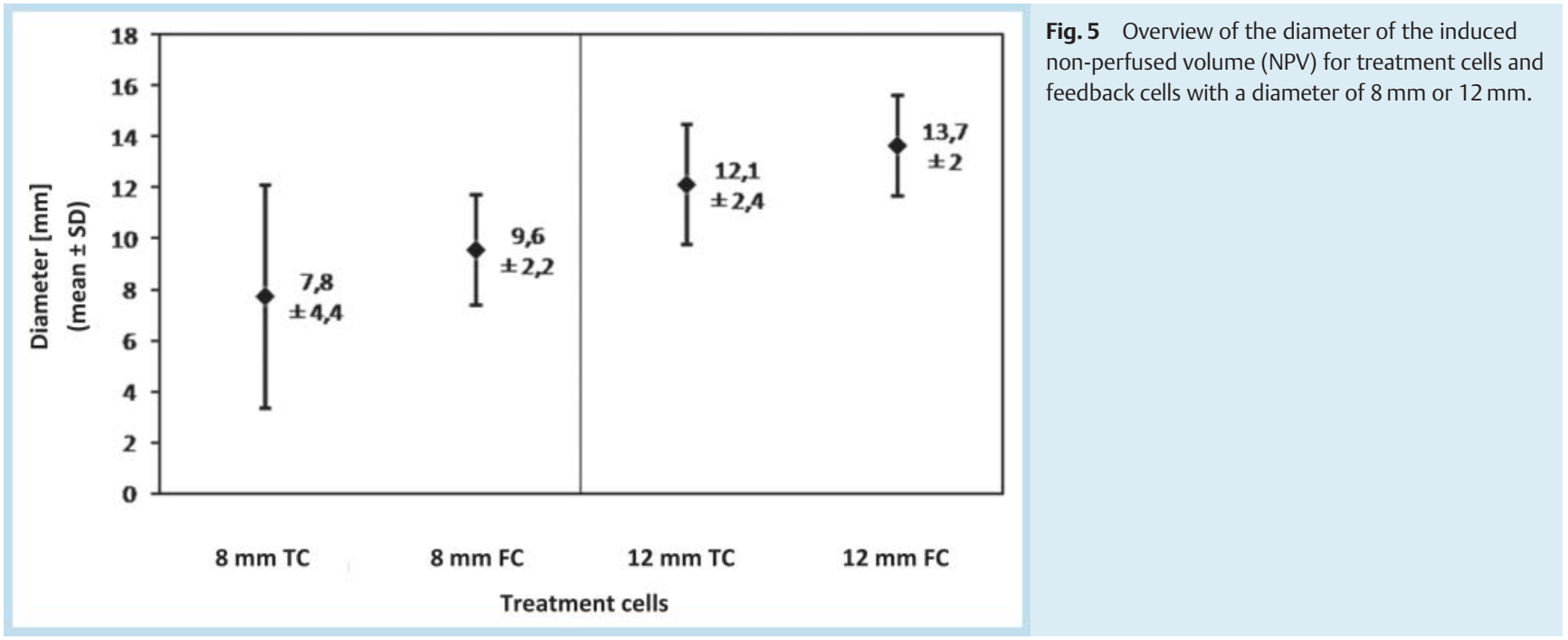

Table 3 Overview of termination criteria for treatment cells

\begin{tabular}{|c|c|c|}
\hline sonication & $\begin{array}{l}\text { absolute treatment } \\
\text { cells (in \%) }\end{array}$ & $\begin{array}{l}\text { absolute feedback } \\
\text { cells (in \%) }\end{array}$ \\
\hline completed & $171(83.4)$ & 65 (28.6) \\
\hline $\begin{array}{l}\text { premature termination } \\
\text { (total) }\end{array}$ & $34(16.6)$ & $162(71.4)$ \\
\hline by operator & $3(1.5)$ & $26(11.4)$ \\
\hline by patient & $7(3.4)$ & $3(1.2)$ \\
\hline software-induced & $2(1)$ & $113(50)$ \\
\hline by safety system & $5(2.4)$ & $1(0.5)$ \\
\hline other & $17(8.3)$ & $19(8.3)$ \\
\hline total & 205 & 227 \\
\hline
\end{tabular}

size are smaller $(\mathrm{p}=0.0000002)$. On the whole, the FC show a good correlation to the planned cell diameter $(r=0.79)$ in contrast to the TC $(r=0.38)$. $\odot$ Fig. 5 shows the average diameter of the induced termination of perfusion for cells with a diameter of $8 \mathrm{~mm}$ or $12 \mathrm{~mm}$.

In total, slightly more power was used in the case of the feedback-regulated cells: $134 \pm 26 \mathrm{~W}(80-130)$ vs. $124 \pm 32 \mathrm{~W}$ $(70-200), p=0.0002$.

\section{Tolerability}

No abnormalities were detected in the post-therapeutic clinical examination or in the contrast-enhanced MRI follow-up examination. Neither neurological damage nor reddening of the skin occurred. $\bullet$ Table 4 shows the summary of the level of pain specified by the patients before, during, and immediately after treatment. $39 \%$ of the patients never complained of pain. All patients experienced only mild pain or no pain in the post-interventional monitoring phase. Severe pain during treatment was specified in only 3 cases resulting in treatment termination in 2 of the cases. In the other case, the pain was so brief that treatment was able to be continued. In one case, the pain occurred in the area of a C-section scar at the edge of the ultrasound field and in the other cases lumbar and sacral nerve pain occurred. The reproducible occurrence of moderate pain in the sacral area during sonication resulted in the termination of another treatment.
Only 2 remarkable findings were seen in the one-month follow-up period. One patient experienced increased first post-therapeutic menstruation bleeding, and another patient complained of significant pain in the lower abdomen 2 weeks after treatment for a period of several days. However, this pain could not be assigned to a morphological correlate during MRI examination.

\section{Volume reduction}

In the reevaluated patients the myoma volume was able to be reduced after 1 month by $28 \pm 21 \%(7-53)$ from $108 \pm 129 \mathrm{ml}$ $(6-411)$ to $81 \pm 97 \mathrm{ml}(5-312)(\mathrm{p}=0.003)$. After 6 months, the volume reduction was $45 \pm 21 \%(5-100)$, and the average myoma volume had decreased to $65 \pm 85 \mathrm{ml}(0-323)$ $(\mathrm{p}=0.001)$ ( $\bullet$ Fig.6). $\bullet$ Fig. 7 shows an example of the progression of size reduction after successful treatment.

\section{Symptom reduction}

The symptoms determined via the UFS-QoL questionnaire were also able to be significantly reduced. The initial SSS of $51 \pm 16$ points $(28-75)$ of all reevaluated patients was able to be reduced to $44 \pm 17$ points $(22-75)(\mathrm{p}=0.14)$ after one month, and by a total of 14 points to $37 \pm 17$ points $(9-66)$ after six months ( $\mathrm{p}=0.001$ ) ( $\bullet$ Fig. 8). 9 of the 13 follow-up patients showed a reduction of the SSS of $\geq 10$ points.

\section{Discussion}

$\nabla$

MR-guided HIFU treatment of uterine fibroids is an effective and reliable method that is completely noninvasive and gentle. The MR-HIFU system in this study uses a novel form of volumetric sonication of large treatment cells with a diameter of up to $16 \mathrm{~mm}$, which involves electronically steering the ultrasound focus in outwardly moving concentric circles ( $\bullet$ Fig. 1 ). This mechanism ensures higher energy efficiency due to the use of the radial expansion of the thermal energy when heating an inner circle from the next concentric circle [15]. The used feedback mechanism is intended to ensure homogeneous, sufficient heating and thus reliable, constant ablation results regardless of the tissue properties. 


\begin{tabular}{|lllllll|} 
level of pain & & $\mathbf{0}$ (none) & $\mathbf{1}$ (minor) & $\mathbf{2}$ (moderate) & $\mathbf{3}$ (severe) & mean \\
\hline $\begin{array}{lllll}\text { number of patients } \\
\text { (in \%) }\end{array}$ & prior to treatment & $15(83)$ & $3(17)$ & 0 & 0 & 0.2 \\
\cline { 2 - 6 } & during & $7(39)$ & $4(22)$ & $4(22)$ & $3(17)$ & 1.2 \\
\cline { 2 - 7 } & after treatment & $13(72)$ & $5(28)$ & 0 & 0 & 0.3
\end{tabular}

Table 4 Pain experienced by patients before, during, and after treatment

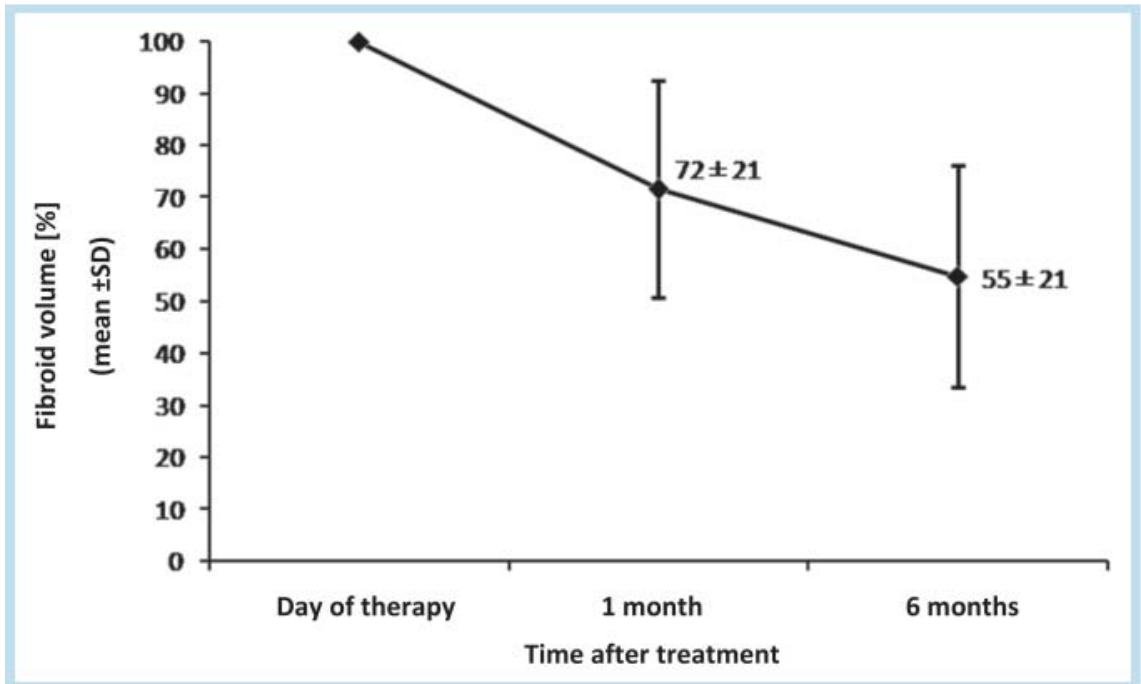

Fig. 6 Post-therapeutic change of the myoma volume in \%.

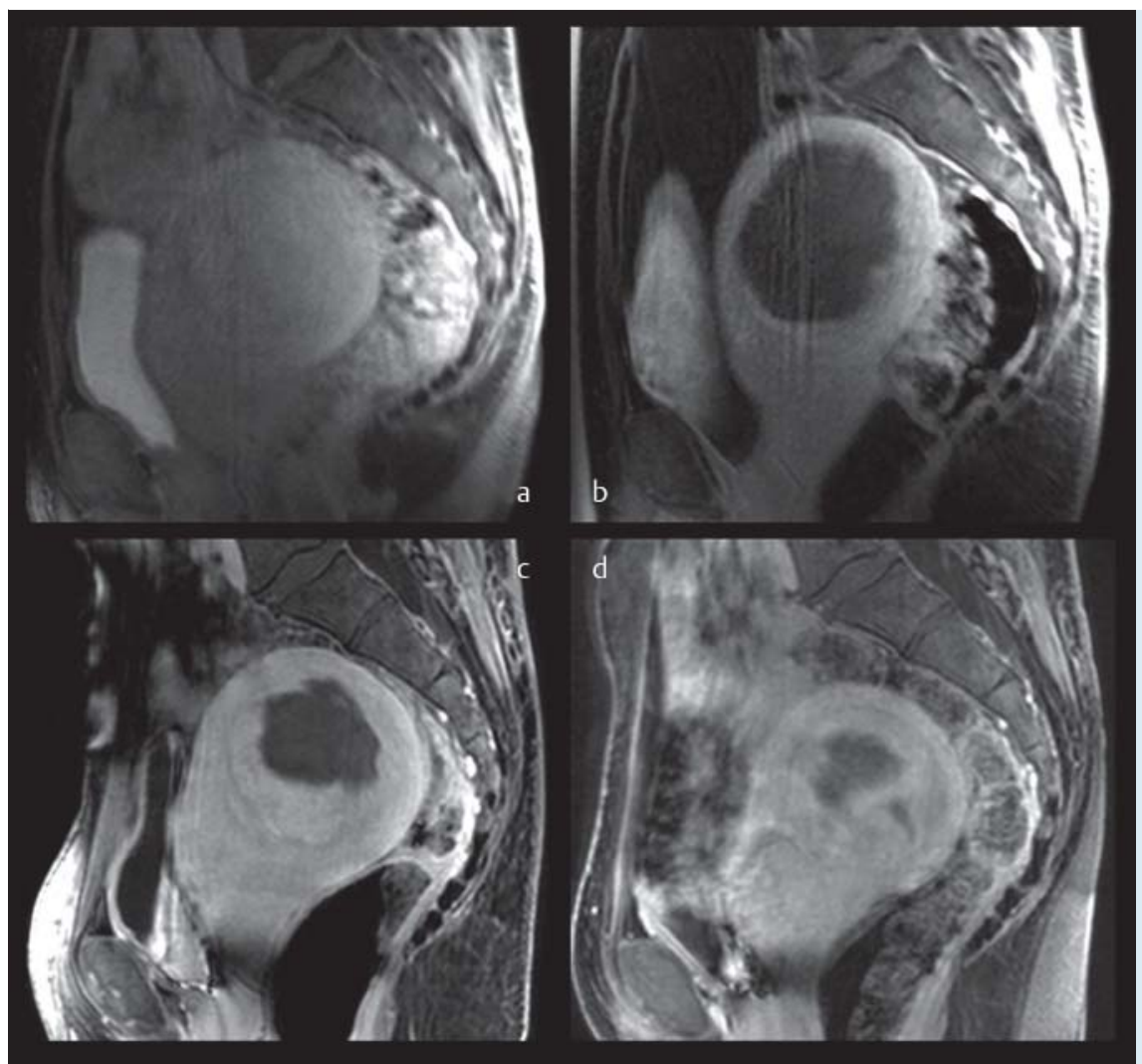

Fig. 7 Exemplary size development. The example shows a large singular myoma prior to treatment (a, $234 \mathrm{ml}$ ), immediately after treatment $\mathbf{b}$, one month after treatment $(\mathbf{c}, 163 \mathrm{ml})$, and six moths postintervention (d, $131 \mathrm{ml})$. The hypointense area in $\mathbf{b}$ corresponds to the non-perfused volume in terms of induced necrosis which cicatrizes and shrinks over time.

The use of previously introduced feedback mechanisms was always based on the estimation of the intraorganic energy absorption as well as the thermal diffusion. However, valid, reliable feedback regulation is not possible without this knowledge. The novel feedback mechanism is independent of such difficult-to-predict tissue parameters and thus is significantly more robust and reliable. In the present study the FC reached higher temperatures in the case of successful sonication and induced greater non-perfused volumes than the TC with lower variability. However, the ablation slightly 


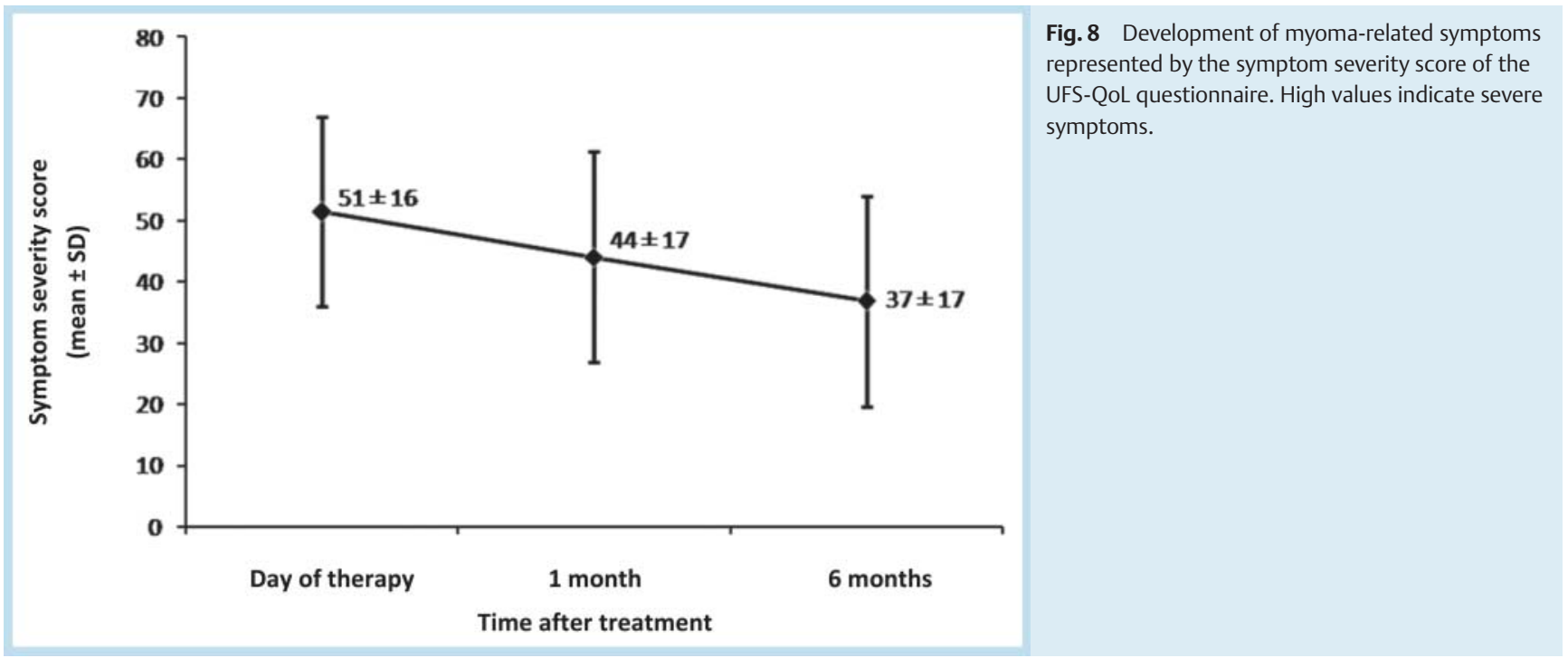

exceeds the planned area. The high rate of feedback sonications that were not completed according to protocol complicates the comparability of the ablation results. A rate of only $28.6 \%$ of sonications evaluated by the system as being completed properly reduces the clinical practicability of feedback control. The following can result in a feedback sonication of a submaximal duration: Particularly in the case of small treatment volumes, partial volume effects at a thermometry slice thickness of $7 \mathrm{~mm}$ seem to be problematic. Dislocations due to movement during sonication and resulting motion artifacts in the phase contrast representation of the temperature can hinder feedback regulation since the system cannot differentiate between phase differences due to motion and those due to temperature gradients. If sonication is performed with insufficient power, the feedback algorithm criteria that control the transition from the inner to the outer trajectories of the focus path and the completion of sonication are not fulfilled. The power to be applied was determined by a test sonication with low power. The full system power was not always utilized at the start of the learning curve. Due to the still high NPV, it can be assumed that even the feedback sonications terminated by the system resulted in effective ablations. This remains a topic for further systematic analyses. In addition, the current release includes improved software and a new transducer with increased maximum power. The first experiences with the new release show a significantly improved efficiency of the FC with substantially fewer terminations.

An NPV ratio of $23 \pm 15 \%$ is relatively low but corresponds approximately to the results of previous studies regarding the effectiveness of HIFU using similarly restrictive safety parameters [7, 17]. Examinations in which ablation rates of up to $76.9 \%$ were achieved were much more aggressive and decreased the safety distances with respect to the serosa to $2.5 \mathrm{~mm}$. However, due to the initially limited experience of the operator and the lack of study results regarding the precision of the volumetric sonication used here at the time of the treatments, generous safety distances were maintained during the present study to ensure patient safety. However, with increasing experience it is possible to ablate increasingly aggressively without sacrificing patient comfort and safety.
The use of large treatment cells is accompanied by increased energy efficiency, resulting in a relative reduction in treatment time [19]. However, maintaining generous safety distances resulted in limited applicability of large treatment cell volumes. If these are reduced in the future, the efficiency can be further increased. Until the safety limits are reduced, use for larger myomas remains limited. This is also reflected in the treatment time which could not be reduced compared to previous studies [17]. In total, the treatment time remains a limiting factor of HIFU treatment.

The goal of the feedback mechanism is to ensure a sufficient sonication as well as to prevent excessive temperature increases, thus further increasing patient safety [16]. Multiplanar real-time MR thermometry makes it possible to effectively monitor the ablation volume and structures at an increased risk in the near and far field [20]. Particularly when ablating larger volumes, there is a risk of heat accumulation in the near field. However, no undesired lesions occurred in this study. The majority of patients did not experience any pain. The average pain level soon after treatment had already returned to the pretherapeutic level. In the case of symptomatic myomas, HIFU supplements the radiological interventional spectrum that is characterized by minimal invasiveness. In comparison to UAE which can be associated with pain during interventions and with a postembolization syndrome in $10 \%$ of cases [21, 22], HIFU is a very low-pain to painless treatment option that can consequently be performed without problem on an outpatient basis. Treatment had to be stopped in $11 \%$ of the patients in our series due to pain during HIFU. The complete prevention of pain-related treatment terminations is desirable since this is a gentle technique. A more stringent analgesic regime, e.g., with intravenous opioids, which were not used in this study, is a possibility for this purpose. The ovaries are also not exposed to radiation in HIFU compared to UAE. Both interventional methods have a very short recovery time compared to surgery.

The achieved reduction of the myoma volume of $45.8 \%$ after 6 months is in agreement with previous studies with reduction rates of $13.5-46 \%[17,23,24]$. Different reasons for the increase in volume reduction beyond the NPV are being dis- 
cussed. In addition to induced cell death as part of the socalled bystander effect according to which damaged cells in the myoma cause apoptosis of surrounding undamaged cells via intercellular signal transduction [25], the posttherapeutic formation of an intracapsular edema is responsible for the expanded tissue damage [26]. Cells on the edge of the tissue heating that are not exposed to a lethal thermal dose but to a sufficiently high temperature to induce defects in the cellular structure are limited by defective supply in their repair mechanisms. The optimum treatment plan or the most efficient sonication strategy remains unclear since the above effects cannot be precisely predicted. Therefore, a number of workgroups are currently addressing the influence of different tissue parameters, how they are visualized in MRI, and the effect of treatment cell size and energy on treatment time and outcome.

In addition to the volume reduction, HIFU treatment results in an effective reduction of symptoms which can be objectivized by a reduction of the symptom severity score or an increase in the quality of life score. In a study recently published by Kamp et al., the UFS-QoL of 64.7 prior to treatment was able to be significantly and continuously increased via HIFU to 82.8 after 12 months [27]. In our study the SSS was lowered by an average of 14 points and the symptoms were thus significantly improved. Other previous HIFU studies in which the UFS-QoL was also used even showed an average reduction of the SSS of 20 [28] to 30 points [7] after 6 months with a similar volume reduction. Particularly when treating large volumes, the resorption of the necrotic tissue was not yet complete after 6 months. A further volume and symptom reduction over time consequently seems possible.

In summary, the application of volumetric sonication with feedback regulation results in homogeneous heating and sufficient necrotization without the induction of undesired lesions or the occurrence of other treatment-related side effects and is therefore an effective and safe treatment method. The myoma volume and the accompanying symptoms were able to be significantly reduced, and the application of aggressive treatment schemas with treatment of larger volumes can further increase treatment success in the future.

\section{References}

1 Stewart EA. Uterine fibroids. Lancet 2001; 357: $293-298$

2 Chavez NF, Stewart EA. Medical treatment of uterine fibroids. Clin Obstet Gynecol 2001; 44: $372-384$

3 Kröncke TJ. Myomembolisation in Deutschland: unbekannt, ungenutzt, ungewollt? Fortschr Röntgenstr 2010; 182: $563-564$

4 Luciano AA. Myomectomy. Clin Obstet Gynecol 2009; 52: 362 - 371

5 Rabinovici J, Inbar Y, Revel A et al. Clinical improvement and shrinkage of uterine fibroids after thermal ablation by magnetic resonance-guided focused ultrasound surgery. Ultrasound Obstet Gynecol 2007; 30: $771-777$

6 Stewart EA, Gedroyc WM, Tempany CM et al. Focused ultrasound treatment of uterine fibroid tumors: safety and feasibility of a noninvasive thermoablative technique. Am J Obstet Gynecol 2003; 189: 48 - 54

7 Fennessy FM, Tempany CM, McDannold NJ et al. Uterine leiomyomas: MR imaging-guided focused ultrasound surgery - results of different treatment protocols. Radiology 2007; 243: 885-893
8 Chapman A, ter Haar G. Thermal ablation of uterine fibroids using MRguided focused ultrasound - a truly non-invasive treatment modality. Eur Radiol 2007; 17: 2505-2511

9 Seror O, Lepetit-Coiffe M, Le Bail B et al. Real time monitoring of radiofrequency ablation based on MR thermometry and thermal dose in the pig liver in vivo. Eur Radiol 2008; 18: 408-416

10 Harris GR. FDA regulation of clinical high intensity focused ultrasound (HIFU) devices: Conference proceedings: ... Annual International Conference of the IEEE Engineering in Medicine and Biology Society. IEEE Engineering in Medicine and Biology Society. Conference. 2009, 145-148

11 Ishihara $Y$, Calderon $A$, Watanabe $H$ et al. A precise and fast temperature mapping using water proton chemical shift. Magn Reson Med 1995; 34: 814-823

12 Sapareto SA, Dewey WC. Thermal dose determination in cancer therapy. Int J Radiat Oncol Biol Phys 1984; 10: 787-800

13 Froeling V, Scheurig-Muenkler C, Steffen IG et al. Änderung der gesundheitsbezogenen Lebensqualität und der klinischen Beschwerdestärke nach Uterusarterienembolisation bei symptomatischer Adenomyosis uteri evaluiert mittels standardisiertem Fragebogen. Fortschr Röntgenstr 2012; 184: 48-52

14 Spies JB, Coyne K, Guaou GuaouN et al. The UFS-QOL, a new diseasespecific symptom and health-related quality of life questionnaire for leiomyomata. Obstet Gynecol 2002; 99: 290-300

15 Kohler MO, Mougenot C, Quesson B et al. Volumetric HIFU ablation under 3D guidance of rapid MRI thermometry. Med Phys 2009; 36: $3521-3535$

16 Enholm JK, Kohler MO, Quesson B et al. Improved volumetric MR-HIFU ablation by robust binary feedback control. IEEE Trans Biomed Eng 2009; 57: $103-113$

17 Hindley J, Gedroyc WM, Regan L et al. MRI guidance of focused ultrasound therapy of uterine fibroids: early results. Am J Roentgenol Am J Roentgenol 2004; 183: 1713-1719

18 Zhang L, Chen WZ, Liu YJ et al. Feasibility of magnetic resonance imaging-guided high intensity focused ultrasound therapy for ablating uterine fibroids in patients with bowel lies anterior to uterus. Eur J Radiol 2009; 73: 396 - 403

19 Kim YS, Keserci B, Partanen A et al. Volumetric MR-HIFU ablation of uterine fibroids: Role of treatment cell size in the improvement of energy efficiency. Eur J Radiol 2012; 81: 3652 - 3659

20 Eckey T, Neumann A, Bohlmann MK et al. Nichtinvasive Thermoablation symptomatischer Uterusmyome mit MR-gesteuertem hochenergetischem Ultraschall. Radiologe 2011; 51: 610-619

21 Emons G, Kiesel L, Runnebaum I et al. Kommentar der Kommission Uterus der AGO zum Konsensuspapier des 3. Radiologisch-gynäkologischen Expertentreffens zur Behandlung von Uterusmyomen durch Uterusarterienembolisation (UAE) in München, 15. Januar 2010. Fortschr Röntgenstr 2010; 182: 1016-1017

22 Kröncke T, David M. Uterusarterienembolisation (UAE) zur Myombehandlung - Ergebnisse des 3. radiologisch-gynäkologischen Expertentreffens. Fortschr Röntgenstr 2010; 182: 615-617

23 Funaki K, Fukunishi H, Funaki T et al. Mid-term outcome of magnetic resonance-guided focused ultrasound surgery for uterine myomas: from six to twelve months after volume reduction. J Minim Invasive Gynecol 2007; 14: 616-621

24 LeBlang SD, Hoctor K, Steinberg FL. Leiomyoma shrinkage after MRIguided focused ultrasound treatment: report of 80 patients. Am J Roentgenol 2010; 194: 274-280

25 Niu H, Simari RD, Zimmermann EM et al. Nonviral vector-mediated thymidine kinase gene transfer and ganciclovir treatment in leiomyoma cells. Obstet Gynecol 1998; 91: 735 - 740

26 McDannold N, Tempany CM, Fennessy FM et al. Uterine leiomyomas: MR imaging-based thermometry and thermal dosimetry during focused ultrasound thermal ablation. Radiology 2006; 240: 263-272

27 Kamp JE, David M, Scheurig-Muenkler C et al. Klinische Ergebnisse der Behandlung symptomatischer Uterusmyome mittels MRgFUS (Magnetresonanztomographie-gesteuerter fokussierter Ultraschall). Fortschr Röntgenstr 2013; 185: 136-143

28 Funaki K, Fukunishi H, Sawada K. Clinical outcomes of magnetic resonance-guided focused ultrasound surgery for uterine myomas: 24month follow-up. Ultrasound Obstet Gynecol 2009; 34: 584-589 